\title{
A Study of Changes in Risk Appetite in the Stock Market and the Housing Market before and after the Global Financial Crisis in 2008 Using the vKOSPI
}

\author{
Jin Yong Yang ${ }^{1 *}$, Sang-Heon Lee ${ }^{2}$ \\ ${ }^{1}$ Hankuk University of Foreign Studies, Seoul, South Korea \\ ${ }^{2}$ Hanyang University, Seoul, South Korea \\ Email: ${ }^{*}$ jyang0112@gmail.com,paco@hanyang.ac.kr
}

Received October 7, 2013; revised November 5, 2013; accepted November 15, 2013

Copyright (C) 2013 Jin Yong Yang, Sang-Heon Lee. This is an open access article distributed under the Creative Commons Attribution License, which permits unrestricted use, distribution, and reproduction in any medium, provided the original work is properly cited.

\begin{abstract}
This study analyzes the empirical relationship between the vKOSPI, which is the Korean VIX (implied volatility index), and the housing market (rent ${ }^{1}$-to-house price ratio) based on monthly data from January 2003 to November 2012 . The data were divided into two parts before and after the global financial crisis in 2008 and were analyzed by using the Vector Autoregressive (VAR) Model. The research results show that the influence of vKOSPI on the housing market changes from symmetric to asymmetric since the global financial crisis in 2008. Before the global crisis in 2008, the influence of the vKOSPI on the house price index and rent index is almost the same, so the influence on the rent-to-house price ratio is not statistically significant. However, since the global crisis in 2008 , the influence of the vKOSPI on the two prices has changed asymmetrically and the influence on the rent-to-house price ratio was statistically significant. Second, the influence of the vKOSPI fluctuation on house sale prices and rent is shown differently according to the rise/fall of the vKOSPI. In the event of the vKOSPI rising, house prices would fall greatly. On the other hand, in the event of the vKOSPI falling, the rise in housing prices is relatively small. This means that while the boosted sentiment of investors in the stock market is not transferred to the housing sales market, the aggravated sentiment of investors affects the housing sales market easily. In conclusion, the uncertainty has been represented in the vKOSPI and the preference for risky assets has an asymmetrical influence on the market dependent upon the kind of market. We suspect that this is caused by complex factors including shrinking expectations for future house prices.
\end{abstract}

Keywords: Risk Appetite; Stock Market; Housing Market; Implied Volatility Index

\section{Introduction}

The major factors that influence the housing market are economic circumstances (this is a fundamental factor), economic bubbles, and policies. Since a house is a risky asset, it is affected by the sentiment of investors. The global financial crisis in the latter half of 2008 began in the USA and spread worldwide. It originated from the real estate crisis. It is widely recognized that rapid fluctuation of real estate prices had a negative influence on the economy. Most economic specialists suspect that low interest rates and excessive mortgage loans created the

\footnotetext{
*Corresponding author.

${ }^{1}$ This means "Jeonse" price, deposit money for housing lease. "Jeonse" is a unique system of Korea. A lessee deposits a certain amount of money to the owner during the lease period and gets back the full amount of the money at the end of leasing.
}

soaring house prices in the USA, and the fall of the collateral value of a house due to the collapse of the housing bubble generated inferior assets in the banks.

Rise of real estate prices stimulates economic activities by the wealth effect and increases investment and consumption expenditures. This also indirectly increases the demands for loans. The rise of real estate prices increases the collateral value of the borrowers. This is called the financial accelerator effect (Bernanke et al. [1]).

In particular, from 2009 to 2012, the rise of rent is greater than the rise of house sale prices in the Korean housing market, most of which is interpreted as due to the changes in the sentiment of investors. Notwithstanding, there is no specific problem in housing supply, people have come to prefer renting compared to the purchase of a house when choosing their residence. Therefore, it is 
interpreted that the sentiment of investors toward the housing market has changed.

According to a news article ${ }^{2}$, rental prices have continuously risen since the global financial crisis and there have been an increasing number of loans given for providing a rental deposit. In particular, due to the rise of rentals, the total market price of rentals nationwide reaches almost half of the total market price of house sales. The key point of the article is that there is a lot of demand for rental properties, but consumers are not shifting to the sales market. This is because investors believe that paying a rental deposit is better than buying a house which has a larger debt burden.

The vKOSPI is a volatility index that represents the future outlook of investors who participate in stock market. It is also referred to as the "fear index".

In the USA, the VIX, an index to represent volatility of the stock market, is used as an overall measure that shows uncertainty (e.g. Bloom [2]). The Korean Volatility Index, vKOSPI, also represents the degree of uncertainty that Korean investors feel at a given moment. According to Chauvet, Gabriel and Lutz [3], VIX, the index representing the attitude of investors who participate in the stock market with a focus on risk, and the Housing Distress Index (HDI) from the housing market demonstrate a very similar pattern. Therefore, the vKOSPI also may be considered to be connected with the psychological flow of investors.

This study analyzes the influence of the attitude or risk appetite of investors towards risky assets, which is represented as the KOSPI Volatility Index (vKOSPI), on the housing market.

The distinctive features of this study compared to previous studies are outlined below.

First, this study investigates the relationship between the vKOSPI and the housing market, unlike other studies that analyze the relationship between the housing sales market and rental market. Few studies have been conducted in that way so far.

Second, using the house price to rent ratio, it aims to have consistency with the index that is mainly used by market participants.

Third, it analyzes the influence of the vKOSPI on the housing market before and after the global financial crisis in 2008 using the VAR model.

Major research results are explained below.

First, the influence of the vKOSPI on the housing market before and after the global financial crisis in 2008 changed from symmetric to asymmetric. Before the economic crisis in 2008, the influences of the vKOSPI on

\footnotetext{
${ }^{2}$ News article from the internet, "The rent soared up... scarcity for rental "Concerning on rental shortage", http://news.naver.com/main/read.nhn? mode $=$ LSD\&mid $=$ sec \&sid $1=101 \&$ oid $=001$ \&aid $=0006356773$
}

the house price index and rent index are very similar to each other, symmetrically that is, the influence on the rent-to-house price ratio is not statistically significant. It is because the vKOSPI has a similar influence on both the denominator and numerator of the rent-to-house price ratio. However, after the economic crisis in 2008, the effect of the vKOSPI is asymmetric, which is statistically significant.

Second, the vKOSPI has a bigger influence on the rent index than the house price index. This is a very interesting point. To explain in more detail, when the vKOSPI falls, both rent and house prices rise. However, the rise in rent prices is larger than the rise in house prices, which makes the changes in rent-to-house price ratio bigger.

On the other hand, when the the vKOSPI rises, both rent and house prices fall. In that case, the fall in house prices is larger than the fall in rents, which makes the changes in rent-to-house price ratio smaller. This means that the vKOSPI fluctuation had different influences on house prices and rent according to the rise/fall of the vKOSPI. Although the sentiment of participants in the stock market is boosted due to the fall of the vKOSPI, the prices in the rental market rise more than the housing market. It means that the boosted sentiment of investors in the stock market does not often shift to the housing market. It also means that although the sentiment of participants in the stock market is aggravated due to the rise of the vKOSPI, the fall of house prices is much bigger than the rental market, causing the stock market to easily affect the housing market. 1) When the risk appetite of investors changes in regard to the uncertainty and risk due to the vKOSPI fluctuation, the volatility increases in the rental market more than in the house sales market; and 2) the asymmetric sentiment of investors is transferred from the stock market to the housing market. These results show that investors have a different attitude towards participating in the two markets.

Third, when the vKOSPI rises, the changes in rent-tohouse price ratio increase more than the case when the vKOSPI falls (asymmetric effect). This coincides with a general phenomenon in which the volatility gets bigger when stock prices fall, than the case when stock prices rise. The direction of volatility and the price variable of the housing market show similar patterns.

Last, the vKOSPI "Granger causes" the changes in rentto-house price ratio. This means that the risk attitude of investors who participate, based on uncertainty in stock market, is closely related to the price variable of the housing market.

The structure of the research is as follows. Chapter 2 summarizes previous studies and Chapter 3 summarizes the data. Chapter 4 provides methodology and Chapter 5 presents the results. Chapter 6 offers some conclusions. 


\section{Previous Studies}

Most previous studies focus on the relationship between the stock market and housing market. They deal with the issues concerning whether the two markets are co-integrated or if there is any causality between the two markets. Apergis and Lambrinid is [4] show that the stock market and the real estate market move together toward the same direction (integration of the stock market and real estate market) in the USA and UK by using co-integration and the error correction model with data from 1986 to 2006. They argue that as the integration of two markets is great, a portfolio that contains both stocks and real estate assets have relatively small advantages.

Anoruo and Braha [5] use the GARCH-enhanced VECM model and focus on the rate of returns of the houses and stocks. They insist that there is a co-integration relationship between the two factors. There is a spillover effect from the stock market to the housing market but the spillover effect doesn't occur in the opposite direction.

Sim and Chang [6] find that there is Granger causality from house and land prices to stock prices, but doesn't find Granger causality in the opposite direction.

Tse [7] analyzes the relationship between the stock market and real estate market by using Hong Kong data from 1974 to 1998. As a result, he finds that unexpected change in real estate prices is a main factor that can influence stock prices and that the two markets are co-integrated. As a high portion of real estate-related companies are listed on the stock market, the trend of real estate prices affects the profitability of the real estate-related companies, which in turn has an influence on their stock prices.

Unlike previous studies, this study analyzes the effect of the vKOSPI on the housing market, and also the effect of the investors' attitude toward risk in the housing market. As there are various influential factors that affect the housing market, this study use macroeconomic variables as additional explanatory variables, in order to control the effect.

\section{Data}

\subsection{Relationship between the VIX and the Housing Market Index}

Figure 1 is a graph shown in the paper of Chauvet, Gabriel and Lutz [3] to compare the HDI and VIX. The dotted line represents the VIX, and the solid line the HDI. As shown in Figure 1, the sentiments of investors who participate in the two markets have differences in volatility but very similar patterns in terms of trend.

\subsection{Basic Data}

The data used in model estimation is the house price in-

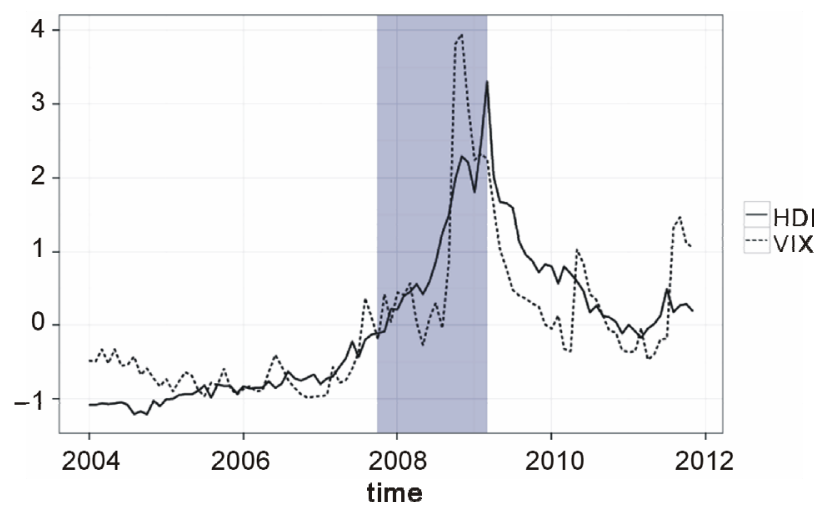

Figure 1. VIX and HDI.

dex, rent index, KOSPI index, consumer price index, index of industrial production, vKOSPI index and estimated data series related to term structure of interest rates. The data related to term structure of interest rates refers to the level and slope factors estimated by the Dynamic Nelson Siegel model (hereafter DNS model) on the spot yield curve of government bonds. The estimated level and slope factor are used instead of the interest rates of government bonds with a specific maturity. This is because of the fact that the term structure of government bonds can be represented in the three factors of level, slope, and curvature ${ }^{3}$.

The data is collected on a monthly basis and the sampling period is from January 2003 to November 2012. ${ }^{4}$ The time series of basic data are shown in Figure 2.

Analyzing the data before and after the global financial crisis triggered by the bankruptcy of Lehman Brothers Holdings in the $3^{\text {rd }}$ quarter of 2008 (hereinafter referred to as the global financial crisis in 2008), we can find a few characteristics. First, the rent-to-house price ratio of a house is falling until the global financial crisis in 2008 , but after the crisis until 2012 it rises. Second, the level of the yield curve since the global financial crisis in 2008 lowers gradually due to expansionary monetary policy in reaction to the crisis, and the term structure of interest rates make a parallel shift downwards. The slope of the yield curve increases dramatically and then gradually decreases over time, eventually returning to a value close to the long-term average. ${ }^{5}$ Table 1 shows the basic statistics of transformed data.

The results found through the analysis of the correlation of Table 1 can be summarized as follows.

First, as for the rent-to-house price ratio, the housing

\footnotetext{
${ }^{3}$ The relationship between the three factors of the term structure of interest rates and economic variables is explained in detail in the research of Diebold et al. [8].

${ }^{4}$ The starting point of the vKOSPI data is January 2003.

${ }^{5}$ The figures of the slope factor in the DNS model are the values of the normal slope to which all, minus (-) was prefixed. Therefore, as the value of the slope factor decreases, the slope of the actual term of the structure increases. See Diebold et al. [8].
} 

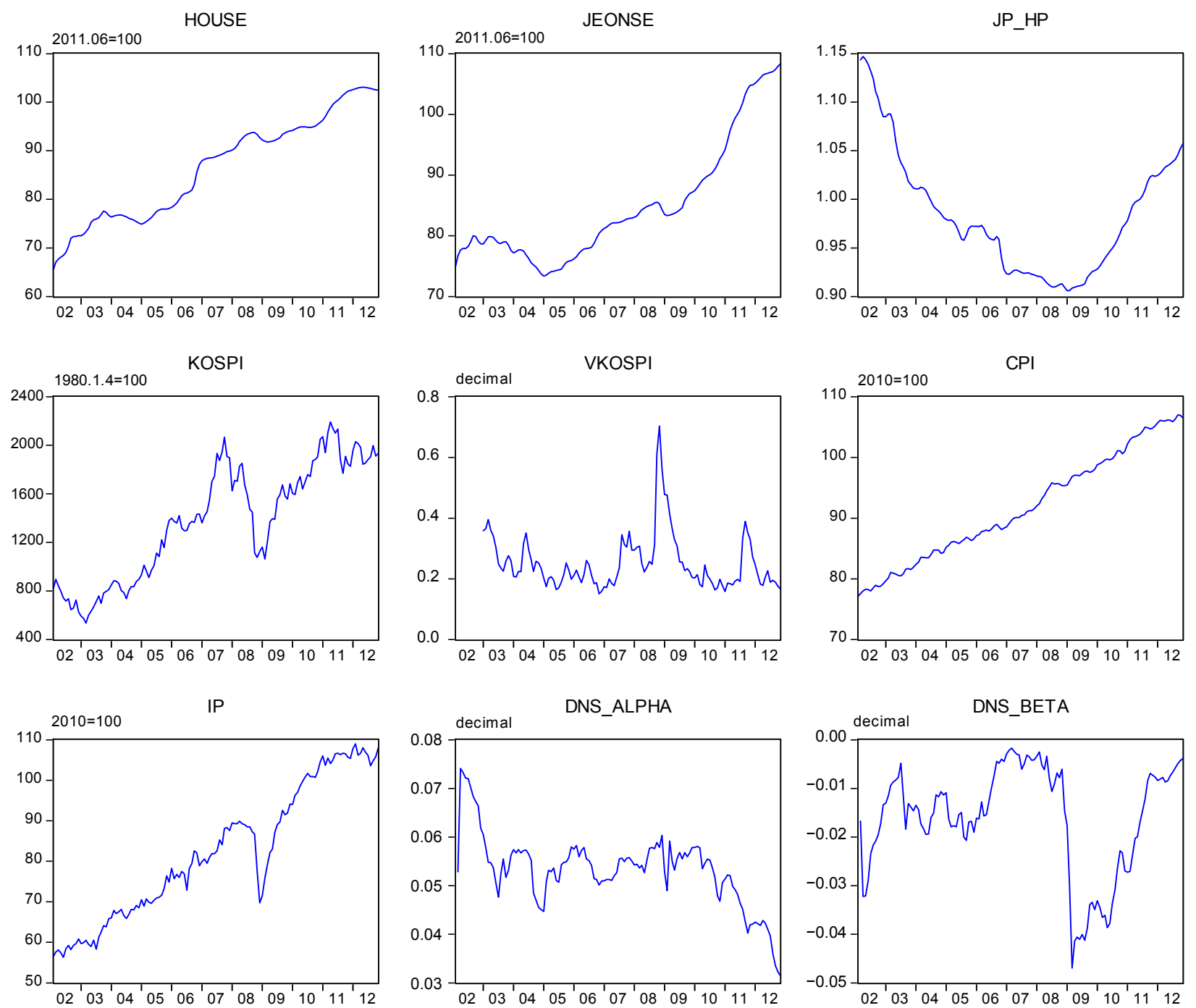

Figure 2. Basic data. "HOUSE: house price index; JEONSE: rent index; JP_HP: rent-to-house price ratio; KOSPI: KOSPI index; vKOSPI: KOSPI 200 volatility index; CPI: consumer price index; IP: index of industrial production; DNS_ALPHA: level factor, and DNS_BETA: slope factor. "The units of basic data for this study are used asis. vKOSPI, DNS_ALPHA and DNS_BETA, were not multiplied by 100 . Therefore, these three sets of data should be read in decimal not in percentage (\%).

market has changed since the global financial crisis in 2008. The rent-to-house price ratio and house prices have a negative (-) correlation between the Pre-crisis period (the period before the crisis) and the Entire period (the whole period of the data covering before and after the crisis). It means that the bigger the changes in the rent-to-house price ratio are, the lower the house prices are. On the contrary, the bigger the changes in house prices are, the smaller the changes in rent-to-house price ratio are. It is because the rise of house prices is bigger than the rise of rents. However, after the global financial crisis in 2008, the correlation between the rent-to-house price ratio and house prices is shown as positive $(+)$. It means that after the global financial crisis in 2008, the higher the changes in rent-to-house price ratio, the higher the rise in house prices. Although it may be an unex- pected result, the correlation between rent-to-house price ratio and rent can justify the result. The correlation between rent-to-house price ratio and rent during the Post-crisis period is 0.857 , which shows that the rise of rents is relatively higher than the rise of house prices. Therefore, from the perspective of market participants, it shows that rents rise higher than house prices do.

Second, the relationship between the stock market and housing market vary according to the attitude of investors towards the markets' direction and risk. The KOSPI index shows positive $(+)$ correlation with house prices, but negative $(-)$ with rental prices. On the other hand, the vKOSPI have a positive $(+)$ relationship with both house and rental prices. It means that whereas the direction of the stock market is correlated with house prices and rentals in opposite directions, the sentiment of investors on 
Table 1. Correlation of the data among pre-crisis, post-crisis, and the entire period of the financial crisis in 2008.

\begin{tabular}{|c|c|c|c|c|c|c|c|c|c|}
\hline & sample & HOUSE & JEONSE & JP_HP & KOSPI & ALPHA & BETA & CPI & IP \\
\hline \multirow{3}{*}{ JEONSE } & Pre-crisis & 0.639 & & & & & & & \\
\hline & Post-crisis & 0.919 & & & & & & & \\
\hline & Entire & 0.576 & & & & & & & \\
\hline \multirow{3}{*}{ JP_HP } & Pre-crisis & -0.582 & 0.253 & & & & & & \\
\hline & Post-crisis & 0.576 & 0.851 & & & & & & \\
\hline & Entire & -0.405 & 0.513 & & & & & & \\
\hline \multirow{3}{*}{ KOSPI } & Pre-crisis & 0.017 & -0.128 & -0.167 & & & & & \\
\hline & Post-crisis & 0.014 & -0.014 & -0.052 & & & & & \\
\hline & Entire & 0.026 & -0.089 & -0.135 & & & & & \\
\hline \multirow{3}{*}{ ALPHA } & Pre-crisis & -0.051 & 0.200 & 0.271 & -0.319 & & & & \\
\hline & Post-crisis & 0.011 & -0.102 & -0.272 & 0.063 & & & & \\
\hline & Entire & 0.055 & -0.116 & -0.199 & -0.040 & & & & \\
\hline \multirow{3}{*}{ BETA } & Pre-crisis & 0.239 & 0.188 & -0.098 & 0.057 & -0.323 & & & \\
\hline & Post-crisis & -0.145 & -0.108 & 0.014 & -0.325 & -0.730 & & & \\
\hline & Entire & 0.129 & -0.172 & -0.311 & -0.130 & -0.353 & & & \\
\hline \multirow{3}{*}{ CPI } & Pre-crisis & -0.171 & 0.117 & 0.344 & -0.167 & 0.231 & 0.011 & & \\
\hline & Post-crisis & 0.135 & 0.099 & 0.017 & 0.139 & 0.142 & -0.257 & & \\
\hline & Entire & -0.069 & 0.073 & 0.156 & -0.035 & 0.179 & -0.072 & & \\
\hline \multirow{3}{*}{ IP } & Pre-crisis & -0.112 & 0.042 & 0.179 & 0.080 & -0.054 & 0.009 & 0.010 & \\
\hline & Post-crisis & 0.259 & 0.246 & 0.156 & 0.197 & -0.050 & -0.423 & 0.256 & \\
\hline & Entire & 0.025 & 0.128 & 0.110 & 0.142 & -0.035 & -0.228 & 0.121 & \\
\hline \multirow{3}{*}{ VKOSPI } & Pre-crisis & -0.206 & -0.247 & -0.020 & -0.264 & 0.339 & 0.081 & 0.053 & -0.076 \\
\hline & Post-crisis & -0.481 & -0.536 & -0.472 & -0.287 & 0.320 & 0.117 & -0.193 & -0.372 \\
\hline & Entire & -0.289 & -0.349 & -0.091 & -0.270 & 0.265 & 0.044 & -0.087 & -0.270 \\
\hline
\end{tabular}

*Pre-crisis: From January 2003 to August 2008; Post-crisis: From September 2008 to November 2012, and Entire period: From January 2003 to November 2012. ${ }^{*}$ House prices, rents, KOSPI index, index of industrial production, and consumer price index were log differentiated. Rent-to-house price ratio was differentiated. The level variables were used as they were for level factor, slope factor, and the vKOSPI.

implied volatility or risk in the stock market have a negative $(-)$ relationship with the two markets.

Third, the correlations of vKOSPI with rents, and house prices show a big difference from the correlation between the vKOSPI and the rent-to-house price ratio. The correlations of vKOSPI with rents, and house prices are negative (-), regardless of the global financial crisis in 2008. One thing that is noteworthy is that the correlation after the crisis in 2008 becomes greater. The relationship between the vKOSPI and the rent-to-house price ratio is also negative $(-)$, but it becomes much greater $(-0.02 \rightarrow-0.472)$ after the crisis in 2008. Before the crisis in 2008, the vKOSPI affect a similar amount of house prices and rents, which is a symmetric influence. However, after the crisis, it has influence of a different size, that is, an asymmetric influence. In other words, before the crisis in 2008, when both the stock market and housing market are on the rise, the attitude of investors participating in the housing sales market and rental mar- ket toward risky assets shows a similar pattern. After the crisis in 2008, however, there is a remarkable difference in the attitude of the investors in the sales market and rental market. It is assumed that the uncertainty in expected rising house prices have influence on the investors' appetite for houses, a risky asset.

Fourth, it is noteworthy that the correlation between the vKOSPI and housing market (sales and rental) after the global financial crisis in 2008 is bigger than the correlation between the vKOSPI and stock market. In particular, the correlation between the vKOSPI and rental/ house prices index before and after the global financial crisis in 2008 is -0.02 , and -0.472 , respectively, which is a significant increase.

Fifth, the industrial production index and consumer price index that represent the basic conditions of the economy over the Entire period show positive $(+)$, and negative $(-)$ relationships with the house prices, respectively. 


\section{Methodology}

Before conducting the analysis on the relationship among the stock market, housing market, and economic variables, unit root and co-integration tests are conducted. The model that is most suitable for the changes before and after the global financial crisis in 2008 is the VAR model.

\subsection{Unit Root Test}

All level variables of basic data have a unit root. Therefore, unit root tests are conducted only on the converted variables and all the results are stationary as shown in Table 2. In particular, the rent index has a unit root even when conducting the first order difference. It becomes stationary after conducting the second order difference. ${ }^{6}$

In the event that the rent-to-house price ratio is used without separating the house prices from rents, stationarity is secured through the first order difference, regardless of setting the unit root test. Although the level and slope factor in DNS model has a unit root, when estimating DNS term structure model, data transformation is not conducted because it is estimated on the assumption that the level and slope factors follow stationary AR(1) processes, respectively. Table 2 shows the results of the unit root test on the variables that form the model.

By rejecting the null hypothesis of the Augmented Dicky-Fuller Test (ADF), insisting that all variables except for level and slope factors have a unit root at the significant level of $5 \%$, we find that the variables are converted to stationary variables.

\subsection{Co-Integration Test}

If all variables have a unit root in I(1), first order differencing makes them stationary time series. However, in case of using first order differenced variables, there is a risk of losing the information about the long-run relationships. The linear or non-linear relationship among difference variables cannot be interpreted as a long-run equilibrium relationship.

In order to find out if a long-term equilibrium relationship exists in the stock market and housing market, a co-integration test is conducted on the KOSPI index and rent-to-house price ratio by log. Tables 3 and 4 show the results with the use of Trace statistics and Max statistics.

As a result of the co-integration test, it is found that there is no consistent co-integration relationship between the KOSPI and rent-to-house price ratio, but a slight relation is found after the global financial crisis in 2008. As for the co-integration relationship between the KOSPI

\footnotetext{
${ }^{6}$ In case of conducting the unit root test, second order difference which contains intercept, or trend and intercept gave a stationary value. If none is included, the result becomes stationary only through the first order difference.
}

Table 2. Results of unit root test on the transformed variables.

\begin{tabular}{ccc}
\hline & t-value & Prob. \\
\hline DL_HOUSE & -4.53471 & 0.0000 \\
DL_JEONSE & -2.07544 & 0.0369 \\
D_JP_HP & -2.56690 & 0.0105 \\
DL_KOSPI & -10.5752 & 0.0000 \\
DNS_ALPHA & -1.33450 & 0.1678 \\
DNS_BETA & -1.18927 & 0.2134 \\
DL_CPI & -8.68155 & 0.0000 \\
DL_IP & -9.80998 & 0.0000 \\
\hline
\end{tabular}

*The meaning of the prefix affixed to the name of variables is as follows: DL: $\log$ difference, D: difference.

Table 3. Co-integration test results using trace statistics.

\begin{tabular}{cccccc}
\hline Sample period & $\begin{array}{c}\text { No. of } \\
\text { CE(s) }\end{array}$ & Eigenvalue & Statistic & $\begin{array}{c}\text { Critical } \\
\text { Value }\end{array}$ & Prob. \\
\hline \multirow{2}{*}{ Pre-crisis } & None & 0.112362 & 11.27182 & 15.49471 & 0.1953 \\
& At most 1 & 0.045503 & 3.166829 & 3.841466 & 0.0751 \\
Post-crisis & None & 0.24687 & 14.46376 & 15.49471 & 0.0711 \\
& At most 1 & $8.51 \mathrm{E}-05$ & 0.004342 & 3.841466 & 0.9462 \\
Entire period & None & 0.093027 & 12.062 & 15.49471 & 0.154 \\
& At most 1 & 0.003712 & 0.442495 & 3.841466 & 0.5059 \\
\hline
\end{tabular}

"Pre-crisis: From January 2003 to August 2008, Post-crisis: From September 2008 to November 2012, and Entire period: From January 2003 to November 2012 .

Table 4. Co-integration test results using Max statistics.

\begin{tabular}{cccccc}
\hline Sample period & $\begin{array}{c}\text { No. of } \\
\text { CE(s) }\end{array}$ & Eigenvalue & Statistic & $\begin{array}{c}\text { Critical } \\
\text { Value }\end{array}$ & Prob. \\
\hline \multirow{2}{*}{ Pre-crisis } & None & 0.112362 & 8.104995 & 14.2646 & 0.3681 \\
& At most 1 & 0.045503 & 3.166829 & 3.841466 & 0.0751 \\
Post-crisis & None & 0.24687 & 14.45942 & 14.2646 & $\mathbf{0 . 0 4 6 6}$ \\
& At most 1 & $8.51 \mathrm{E}-05$ & 0.004342 & 3.841466 & 0.9462 \\
Entire period & None & 0.093027 & 11.61951 & 14.2646 & 0.1258 \\
& At most 1 & 0.003712 & 0.442495 & 3.841466 & 0.5059 \\
\hline
\end{tabular}

*Pre-crisis: From January 2003 to August 2008, Post-crisis: From September 2008 to November 2012, and Entire period: From January 2003 to November 2012 .

and rent-to-house price ratio, it doesn't exist during the Pre-crisis or the Entire period. After the crisis, however, only Max statistics shows that a single co-integration relationship existed while trace statistics shows no co-integration relationship. It can be interpreted that there is a co-integration relationship between the stock market and housing market after the crisis in 2008. Nonetheless, since Max statistics and Trace statistics show different results, this study uses the VAR model which can be used consistently to compare the Pre-crisis, Post-crisis, and Entire period. 


\subsection{VAR Model}

Representing the variables of the VAR model as column vector $X_{t}$, the $\operatorname{VAR}(1)$ model is formed as follows.

$$
\begin{gathered}
X_{t}=A+B X_{t-1}+\epsilon_{t}, \epsilon_{t} \sim N\left(0_{7 \times 1}, \Sigma_{7 \times 7}\right) \\
X_{t}=\left[\begin{array}{c}
\mathrm{d} \log \left(\mathrm{KOSPI}_{t}\right) \\
\mathrm{d}\left(\mathrm{JP}_{t} / \mathrm{HP}_{t}\right) \\
\alpha_{t} \\
\beta_{t} \\
\mathrm{~d} \log \left(\mathrm{IP}_{t}\right) \\
\mathrm{d} \log \left(\mathrm{CPI}_{t}\right) \\
\operatorname{vKOSPI} \mathrm{IS}_{t}
\end{array}\right]
\end{gathered}
$$

Here, dlog represents log difference and d represents difference. The vector of time series variables, $X_{t}$ represents KOSPI volatility, changes in rent (JP)-to-house price (HP) ratio, level factor of interest rate, slope factor of interest rate, growth rate of industrial production (IP), inflation rate, and KOSPI 200 volatility index (vKOSPI), in that order. " $A$ " is a column vector of $7 \times 1$ constant term; and " $\mathrm{B}$ " is $7 \times 7$ coefficient matrix. " $\epsilon_{t}$ " follows multivariate normal distribution in which the average is " $0_{7 \times 1}$ " and covariance is " $\Sigma_{7 \times 7}$ ".

The VAR model is estimated by using the OLS method.

\section{Estimation Results}

\subsection{Estimation of the VAR Model}

Seeing the Tables 5-7, we can identify a few significant exploratory variables before and after the global financial crisis in 2008.

First, the changes in the vKOSPI level have a negative $(-)$ influence on the changes in rent-to-house price ratio after the financial crisis in 2008. The results show the same negative (-) correlation even on the data of the Pre-crisis and Entire period and they are not statistically significant. The vKOSPI may represent risk appetite of investors in the stock market. That is, when the uncertainty increases and the appetite of investors for risky assets decreases proportionally by the rise of the vKOSPI, both rent and house prices fall. In that case, rent (numerator) falls less than house prices (denominator). On the contrary, when the uncertainty decreases and the appetite of investors for risky assets increases proportionally by the fall of the vKOSPI, both rent and house prices rise. In that case, the numerator, rent, rises much higher than the denominator, house prices.

Seeing the asymmetric changes in the rent-to-house price ratio according to the changes in the vKOSPI, we may suspect that when the investors' appetite for the risky assets rises due to the fall of the vKOSPI, house prices will be more responsive than rents, but the actual data shows the contrary. Rather, the result that the rise of

\begin{tabular}{|c|c|c|c|c|c|c|c|}
\hline & KOSPI & JP_HP & ALPHA & BETA & IP & CPI & VKOSPI \\
\hline \multirow[t]{2}{*}{ KOSPI(-1) } & -0.1291 & 0.0051 & 0.0013 & -0.0049 & 0.0734 & 0.0007 & 0.0341 \\
\hline & $(-0.9615)$ & $(0.6269)$ & $(0.3110)$ & $(-0.9481)$ & $(1.6298)$ & $(0.0746)$ & $(0.4823)$ \\
\hline \multirow[t]{2}{*}{ JP_HP(-1) } & 0.1626 & 0.5817 & 0.0913 & -0.0502 & 1.3950 & 0.0109 & 0.5456 \\
\hline & $(0.0912)$ & $(5.4218)$ & $(1.5845)$ & $(-0.7261)$ & (2.3320) & $(0.0922)$ & $(0.5817)$ \\
\hline \multirow[t]{2}{*}{ ALPHA(-1) } & -6.4268 & 0.0404 & 0.8089 & 0.2373 & -0.3138 & 0.0725 & 2.8184 \\
\hline & $(-2.3410)$ & $(0.2448)$ & $(9.1268)$ & (2.2301) & $(-0.3409)$ & $(0.3984)$ & (1.9528) \\
\hline \multirow[t]{2}{*}{$\operatorname{BETA}(-1)$} & -0.8693 & -0.0075 & 0.0138 & 0.9545 & 0.0024 & 0.0792 & 0.3077 \\
\hline & $(-0.6222$ & $(-0.0892)$ & $(0.3051)$ & $(17.6245)$ & $(0.0051)$ & $(0.8548)$ & $(0.4190)$ \\
\hline \multirow[t]{2}{*}{$\operatorname{IP}(-1)$} & 0.1966 & -0.0160 & -0.0053 & -0.0031 & -0.4426 & -0.0303 & 0.0214 \\
\hline & $(0.5799)$ & $(-0.7861)$ & $(-0.4799)$ & $(-0.2339)$ & $(-3.8932)$ & $(-1.3483)$ & $(0.1201)$ \\
\hline CPI(-1) & $(-0.2258)$ & $(1.7328)$ & $(0.0657)$ & $(-0.7577)$ & $(0.6892)$ & $(1.7254)$ & $(-0.0865)$ \\
\hline \multirow[t]{2}{*}{ VKOSPI(-1) } & 0.0819 & -0.0122 & -0.0059 & 0.0024 & -0.0173 & 0.0016 & 0.7707 \\
\hline & $(0.5865)$ & $(-1.4521)$ & $(-1.3170)$ & $(0.4428)$ & $(-0.3692)$ & $(0.1682)$ & (10.4948) \\
\hline \multirow[t]{2}{*}{$\mathrm{C}$} & 0.3322 & -0.0010 & 0.0121 & -0.0137 & 0.0307 & -0.0012 & -0.0928 \\
\hline & $(2.4543)$ & $(-0.1186)$ & $(2.7626)$ & $(-2.6013)$ & $(0.6774)$ & $(-0.1322)$ & $(-1.3038)$ \\
\hline Adj. R-squared & -0.0008 & 0.3993 & 0.6490 & 0.8386 & 0.1775 & 0.0022 & 0.6997 \\
\hline S.E. equation & 0.0598 & 0.0036 & 0.0019 & 0.0023 & 0.0200 & 0.0040 & 0.0314 \\
\hline F-statistic & 0.9926 & 7.2683 & 18.4322 & 49.9730 & 3.0341 & 1.0208 & 22.9685 \\
\hline
\end{tabular}

Table 5. VAR model estimation before the global financial crisis in 2008 .

*The figure in parentheses represents t-value. 
Table 6. VAR model estimation after the global financial crisis in 2008.

\begin{tabular}{|c|c|c|c|c|c|c|c|}
\hline & KOSPI & JP_HP & ALPHA & BETA & IP & CPI & VKOSPI \\
\hline \multirow[t]{2}{*}{ KOSPI(-1) } & -0.1391 & -0.0092 & -0.0143 & 0.0032 & 0.0275 & 0.0055 & -0.0898 \\
\hline & $(-0.9594)$ & $(-2.8630)$ & $(-2.4357)$ & $(0.3866)$ & $(0.4956)$ & $(0.7112)$ & $(-0.7605)$ \\
\hline \multirow[t]{2}{*}{ JP_HP(-1) } & -0.1973 & 0.4462 & -0.0655 & 0.5161 & -4.2910 & -0.5061 & 3.0315 \\
\hline & $(-0.0504)$ & $(5.1468)$ & $(-0.4112)$ & (2.2969) & $(-2.8607)$ & $(-2.4431)$ & $(0.9502)$ \\
\hline \multirow[t]{2}{*}{ ALPHA(-1) } & -7.2605 & -0.0558 & 0.8795 & 0.1734 & -2.6130 & 0.0169 & 8.4658 \\
\hline & $(-3.3490)$ & $(-1.1639)$ & $(9.9843)$ & (1.3943) & $(-3.1484)$ & $(0.1476)$ & (4.7955) \\
\hline \multirow[t]{2}{*}{ BETA(-1) } & -5.3201 & -0.0271 & -0.0816 & 1.0508 & -1.7129 & -0.0065 & 5.1329 \\
\hline & $(-4.0489$ & $(-0.9319)$ & $(-1.5288)$ & (13.9445) & $(-3.4054)$ & $(-0.0941)$ & (4.7974) \\
\hline \multirow[t]{2}{*}{$\operatorname{IP}(-1)$} & -0.5354 & -0.0013 & 0.0186 & -0.0094 & 0.0282 & 0.0082 & 0.9265 \\
\hline & $(-1.3787$ & $(-0.1466)$ & (1.1763) & $(-0.4221)$ & $(0.1899)$ & $(0.3990)$ & (2.9301) \\
\hline \multirow[t]{2}{*}{ CPI(-1) } & -0.9089 & 0.3039 & -0.0712 & 0.0105 & 0.1040 & 0.2826 & 1.6292 \\
\hline & $(-0.3414)$ & (5.1586) & $(-0.6580)$ & $(0.0689)$ & $(0.1020)$ & $(2.0079)$ & $(0.7515)$ \\
\hline \multirow[t]{2}{*}{ VKOSPI(-1) } & 0.1907 & -0.0066 & 0.0028 & -0.0145 & -0.0373 & -0.0056 & 0.7554 \\
\hline & (2.1193) & $(-3.3224)$ & $(0.7758)$ & $(-2.8039)$ & $(-1.0821)$ & $(-1.1829)$ & (10.3081) \\
\hline \multirow[t]{2}{*}{$\mathrm{C}$} & 0.2058 & 0.0050 & 0.0033 & -0.0051 & 0.1183 & 0.0034 & -0.2624 \\
\hline & $(2.3148)$ & $(2.5322)$ & $(0.9092)$ & $(-0.9949)$ & (3.4773) & $(0.7168)$ & $(-3.6245)$ \\
\hline Adj. R-squared & 0.2012 & 0.7284 & 0.9028 & 0.9369 & 0.3867 & 0.1534 & 0.8439 \\
\hline S.E. equation & 0.0591 & 0.0013 & 0.0024 & 0.0034 & 0.0226 & 0.0031 & 0.0481 \\
\hline F-statistic & 2.7996 & 20.1600 & 67.3691 & 106.9870 & 5.5032 & 2.2939 & 39.6024 \\
\hline
\end{tabular}

${ }^{*}$ The figure in parentheses represents $t$ value.

Table 7. VAR model estimation during the Entire period (January 2003-November 2012).

\begin{tabular}{|c|c|c|c|c|c|c|c|}
\hline & KOSPI & JP_HP & ALPHA & BETA & IP & CPI & VKOSPI \\
\hline \multirow[t]{2}{*}{ KOSPI(-1) } & -0.0345 & -0.0026 & -0.0035 & -0.0046 & 0.0761 & 0.0038 & -0.0983 \\
\hline & $(-0.3478)$ & $(-0.5578)$ & $(-0.9661)$ & $(-0.9611)$ & $(2.0104)$ & $(0.6523)$ & $(-1.4066)$ \\
\hline \multirow[t]{2}{*}{ JP_HP(-1) } & -2.1752 & 0.6332 & -0.0187 & 0.0756 & -0.2686 & -0.0779 & 1.7967 \\
\hline & $(-1.5043)$ & $(9.4225)$ & $(-0.3555)$ & (1.0922) & $(-0.4874)$ & $(-0.9277)$ & $(1.7650)$ \\
\hline ALPHA(-1) & $(-1.5876)$ & $(-2.5977)$ & $(21.7820)$ & $(1.7247)$ & $(-0.8672)$ & $(0.5717)$ & (2.7248) \\
\hline \multirow[t]{2}{*}{ BETA(-1) } & -1.2720 & -0.0865 & 0.0015 & 0.9898 & -0.5088 & -0.0056 & 1.1253 \\
\hline & $(-1.9980)$ & $(-2.9244)$ & $(0.0656)$ & (32.4889) & $(-2.0974)$ & $(-0.1525)$ & $(2.5108)$ \\
\hline \multirow[t]{2}{*}{$\mathrm{IP}(-1)$} & 0.2043 & -0.0151 & 0.0141 & -0.0102 & -0.0693 & -0.0075 & 0.1256 \\
\hline & $(0.8293)$ & $(-1.3150)$ & $(1.5724)$ & $(-0.8622)$ & $(-0.7386)$ & $(-0.5262)$ & $(0.7241)$ \\
\hline \multirow[t]{2}{*}{ CPI(-1) } & -0.0329 & 0.2206 & -0.0179 & -0.0368 & 1.1648 & 0.3050 & -0.5072 \\
\hline & $(-0.0200)$ & $(2.8833)$ & $(-0.2989)$ & $(-0.4666)$ & $(1.8568)$ & $(3.1890)$ & $(-0.4377)$ \\
\hline \multirow[t]{2}{*}{ VKOSPI(-1) } & 0.0696 & -0.0042 & -0.0011 & -0.0125 & -0.0437 & -0.0016 & 0.8182 \\
\hline & $(0.9832)$ & $(-1.2701)$ & $(-0.4389)$ & $(-3.6974)$ & $(-1.6183)$ & $(-0.3922)$ & (16.4169) \\
\hline \multirow[t]{2}{*}{$\mathrm{C}$} & 0.0728 & 0.0069 & 0.0015 & -0.0020 & 0.0258 & -0.0001 & -0.0584 \\
\hline & $(1.2635)$ & $(2.5732)$ & $(0.7158)$ & $(-0.7189)$ & $(1.1745)$ & $(-0.0423)$ & $(-1.4413)$ \\
\hline Adj. R-squared & -0.0026 & 0.6223 & 0.8540 & 0.9301 & 0.1033 & 0.0511 & 0.7664 \\
\hline S.E. equation & 0.0625 & 0.0029 & 0.0023 & 0.0030 & 0.0238 & 0.0036 & 0.0440 \\
\hline F-statistic & 0.9575 & 28.5422 & 98.7818 & 223.3569 & 2.9248 & 1.8998 & 55.8412 \\
\hline
\end{tabular}

${ }^{*}$ The figure in parentheses represents t-value. 
house prices is smaller than the rise of rents shows that the investors' appetite for the risky assets, such as stocks, does not totally shift to the housing sales market, in spite of the rise of the investors' appetite for the risky assets. This means that the investors' expectation for the housing market has changed and such a change is more accelerated after the global financial crisis in 2008.

If the investors' appetite for the risky assets falls due to the rise of the vKOSPI, the fall in house prices gets bigger than the fall in rents. It means that when the investors' appetite for the risky assets, such as stocks decreases, their appetite for the risky assets is shifted to the housing sales market.

The reasons for such an asymmetric influence of the vKOSPI on the housing market may be considered from various perspectives. From the perspective of the risk appetite of investors, it is related to the situation where the house price bubble collapses after the global financial crisis and the expectation for the rise of house prices in the future has not recovered yet.

Referring to the correlation analysis in Table 1, the vKOSPI shows a negative (-) relationship with rents and house prices. In terms of relative volatility after the financial crisis in 2008, rents show more asymmetric changes than house prices.

Second, the level factor of the government bond yield curve (ALPHA) has a negative (-) influence on the stock market, which shows the same pattern before and after the financial crisis. During the Pre-crisis, if the term structure moves upwards, the returns of the KOSPI fall $(-6.4268)$ and the level of vKOSPI rises. It is suspected that due to the overall economic contraction triggered by the rise of long-term and short-term interest rates, the rise of stock market growth becomes sluggish and the risk appetite of investors falls (rise of the vKOSPI). It shows the same pattern after the crisis of 2008. The significance of the estimated coefficient is higher and the size of the coefficient is bigger, too. As shown in Table 7, when estimation is made over the Entire period, the significance falls, but the trend of the figures still remain negative (-).

Third, the slope factor (BETA) of the government bond yield curve explains with significance the stagnation of stock market, fall of investor's risk appetite, and slowdown of the economic growth that occur after the global financial crisis in 2008. Slope factor refers to the spread between long-term and short-term and it is defined as the value obtained by multiplying -1 to a slope. As you can see from Table 6, when a slope factor rises (that is, the slope of term structure lowers) the returns of the KOSPI decrease and the level of the vKOSPI rises, which in turn decreases the economic growth rate. As the slope of the term structure is determined mainly by the short-term maturity, the fact that the slope of the term structure flattens means that short-term interest rates are relatively higher than long-term interest rates. It is interpreted as the result of the policies that try to calm down the overheated economy.

Fourth, the relationship between the vKOSPI and slope factor vary depending on explanatory variables. The trend remains the same over the three periods of Pre-crisis, Post-crisis, and the Entire period. That is, 1) In the event that the vKOSPI is an explanatory variable, if vKOSPI level rises, the slope falls; 2) in the event that the slope factor is an explanatory variable, if slope rises, the vKOSPI level rises, too, which contradicts one another. In case of 1), when economic uncertainty increases due to the rise of the vKOSPI level, the government reacts with an expansive monetary policy such as the cutting of interest rates. In case of 2), if the slope of the term structure becomes flat due to the rise of the slope factor, economic instability due to the rise of short-term interest rates of government bonds, have influence on the sentiment of investors in stock market.

\subsection{Granger Causality Relationship}

Conducting a test on causality relationship using the VAR model is called VAR Granger Causality analysis. This study doesn't assume the causal relationships between variables in advance by the economic theories, and use VAR Granger Causality in order to analyze the causality relationship among variables by using given time series.

Table 8 shows the Granger causality relationship between the vKOSPI and rent-to-house price ratio. The Granger causality relationship also changes much before and after the global financial crisis in 2008. There is significant influence on the Granger causality relationship from the vKOSPI to rent-to-house price ratio in the Post-crisis samples, but not vice versa. It is contrary to the research result of Sim and Chang [6] that found Granger causality from house and land prices to stock price, but not vice versa.

\section{Conclusions}

The Housing market is a macroeconomic variable which government and people are the most interested in.

Table 8. Granger-Causality.

\begin{tabular}{ccc}
\hline Sample period & Chi-sq & Prob. \\
\hline Pre-crisis & 2.437605 & 0.1185 \\
Post-crisis & 8.380858 & $\mathbf{0 . 0 0 3 8}$ \\
Entire period & 1.613261 & 0.204 \\
\hline
\end{tabular}

"Pre-crisis: From January 2003 to August 2008, Post-crisis: From September 2008 to November 2012, and Entire period: From January 2003 to November 2012 . 
Among many factors that have influence on the housing market, this study investigates the influence of economic uncertainty or the sentiment/attitude of investors toward risky assets, which is represented in the vKOSPI, on housing market. As a result, the influence of the vKOSPI on the rent-to-house price ratio is insignificant until the financial crisis in 2008 , but it become significant after the crisis. It is insignificant during the pre-crisis period because the influence of the vKOSPI on the rents and house prices is similar in size and their volatility offsets each other (symmetric influence). However, after the crisis, the influence of the vKOSPI on rents is bigger than that on the house prices, which results in a big change in the rent-to-house price ratio (asymmetric influence). It can be interpreted that recent investors avoid a specific market (sales market) and their interest is shifted to another market (rental market). In other words, if the products in housing sales market and rental market are complementary goods before the financial crisis, in current times, the goods in both markets are substitute goods.

Therefore, the focus on the stability policy for housing market, centering on sales market, should be to make investors' risk appetite have a symmetric influence on the market. For example, current revitalization policies for the housing sales market, according to the results of this study, should be not to make investors' risk appetite biased. It may be done by providing policies to lessen regulations or loan conditions in the market that are necessary for complementation.

In a strict sense, the rent-to-house price ratio is not the ratio of rental versus house prices. It is rather a measurement for the housing market. Attitude and sentiment of investors toward risky assets, which is represented in the vKOSPI, have greater influence on the rent-to-house price ratio than before. Therefore, the rent-to-house price ratio can be an index that can represent the investors' sentiment on the housing market or indicate whether the housing market is overheated or not.

\section{REFERENCES}

[1] B. S. Bernanke, M. Gertler and S. Gilchrist, "The Financial Accelerator in a Quantitative Business Cycle Framework," Handbook of Macroeconomics, Vol. 1, No. 1, 1999, pp. 1341-1393.

http://dx.doi.org/10.1016/S1574-0048(99)10034-X

[2] N. Bloom, "The Impact of Uncertainty Shocks," Econometrica, Vol. 77, No. 3, 2009, pp. 623-685. http://dx.doi.org/10.3982/ECTA6248

[3] M. Chauvet, S. Gabriel and C. Lutz, "Fear and Loathing in the Housing Market: Evidence from Search Query Data," Sosial Science Research Network, 2012. http://dx.doi.org/10.2139/ssrn.2148769

[4] N. Apergis and L. Lambrinidis, "More Evidence on the Relationship between the Stock and the Real Estate Market," Briefing Notes in Economics, No. 85, 2011.

[5] E. Anoruo and H. Braha, "Housing and Stock Market Returns: An Application of GARCH Enhanced VECM," The IUP Journal of Financial Economics, Vol. 6, No. 2, 2008, pp. 30-40.

[6] S. Sim and B. Chang, "Stock and Real Estate Markets in Korea: Wealth or Credit-Price Effect," Journal of Economic Research, Vol. 11, No. 1, 2006, pp. 99-122.

[7] R. Y. Tse, "Impact of Property Prices on Stock Prices in Hong Kong," Review of Pacific Basin Financial Markets and Policies, Vol. 4, No. 1, 2001, pp. 29-43. http://dx.doi.org/10.1142/S0219091501000309

[8] F. X. Diebold, G. D. Rudebusch and S. B. Aruoba, "The Macroeconomy and the Yield Curve: A Dynamic Latent Factor Approach," Journal of Econometrics, Vol. 131, No. 1, 2006, pp. 309-338. http://dx.doi.org/10.1016/j.jeconom.2005.01.011

[9] F. X. Diebold and C. Li, "Forecasting the Term Structure of Government Bond Yields," Journal of Econometrics, Vol. 130, No. 2, 2006, pp. 337-364. http://dx.doi.org/10.1016/j.jeconom.2005.03.005

[10] C. R. Nelson and A. F. Siegel, "Parsimonious Modeling of Yield Curves," The Journal of Business, Vol. 60, No. 4, 1987, pp. 473-489. http://dx.doi.org/10.1086/296409 


\section{Appendix A}

\section{A.1. Dynamic Nelson Sigel Model}

Diebold and Li [9] suggested the Dynamic Nelson-Siegel model (DNS model). It is the expansion of the sectional term structure model of interest rates of Nelson-Siegel [10]. As the DNS model is in between the theoretical model and the statistical model, it has been studied often theoretically, as well as in practice. In particular, it is evaluated to have relatively excellent predictability compared to other complicated models. However, this model is difficult in parameter estimation. It is also known that the solution of the model reacts sensitively to the initial value.

The DNS model represented in a state space model consists of observation equations and state equations.

Observation equations:

$$
\begin{aligned}
& y_{t}(\tau)= \alpha_{t}+\beta_{t}\left(\frac{1-\exp (-\tau \lambda)}{\tau \lambda}\right) \\
&+\gamma_{t}\left(\frac{1-\exp (-\tau \lambda)}{\tau \lambda}-\exp (-\tau \lambda)\right)+\epsilon_{t}(\tau) \\
& \epsilon_{t}(\tau) \sim N\left(0, \operatorname{diag}\left(\sigma(\tau)^{2}\right)\right)
\end{aligned}
$$

State equations:

$$
\begin{gathered}
{\left[\begin{array}{c}
\alpha_{t}-\mu_{\alpha} \\
\beta_{t}-\mu_{\beta} \\
\gamma_{t}-\mu_{\gamma}
\end{array}\right]=\left[\begin{array}{ccc}
\phi_{\alpha} & 0 & 0 \\
0 & \phi_{\beta} & 0 \\
0 & 0 & \phi_{\gamma}
\end{array}\right]\left[\begin{array}{c}
\alpha_{t-1}-\mu_{\alpha} \\
\beta_{t-1}-\mu_{\beta} \\
\gamma_{t-1}-\mu_{\gamma}
\end{array}\right]+\left[\begin{array}{c}
\eta_{\alpha t} \\
\eta_{\beta t} \\
\eta_{\gamma t}
\end{array}\right]} \\
\eta_{t} \sim N(0, Q), \quad Q=\left[\begin{array}{ccc}
\sigma_{\alpha}^{2} & 0 & 0 \\
0 & \sigma_{\beta}^{2} & 0 \\
0 & 0 & \sigma_{\gamma}^{2}
\end{array}\right]
\end{gathered}
$$

The variables used in the above equations and the meaning of parameters are as follows.

\begin{tabular}{cc}
\hline Notation & Meaning \\
\hline$\tau$ & remaining maturity \\
$y_{t}(\tau)$ & spot yield curve \\
$\alpha_{t}, \beta_{t}, \gamma_{t}$ & level, slope, and curvature factors \\
$\mu_{\alpha}, \mu_{\beta}, \mu_{\gamma}$ & long-term (unconditional) average of level, slope, \\
$\phi_{\alpha}, \phi_{\beta}, \phi_{\gamma}$ & and curvature factors \\
$\lambda$ & first order auto regressive coefficients of level, \\
$\epsilon_{t}(\tau)$ & slope, and curvature factors \\
$\sigma(\tau)^{2}$ & measurement error of observation equation \\
$\eta_{\alpha t}, \eta_{\beta t}, \eta_{\gamma t}$ & prediction error of the state equation \\
$\sigma_{\alpha}^{2}, \sigma_{\beta}^{2}, \sigma_{\gamma}^{2}$ & prediction error variance of the state equation
\end{tabular}

Equation (1) is an observation equation. It means that the spot yield curve is represented in the function of unobserved latent factors. $\epsilon_{t}(\tau)$ is a measurement error. It represents the part that is unexplained by the three factors. It is assumed that the covariance matrix of the measurement error follows multi-variant normal distribution of which the average is 0 and the principle diagonal element is $\sigma(\tau)^{2}$.

The state equation in Equation (2) represents the dynamics of three unobserved latent factors that decide yield curve: level, slope, and curvature. The Equation assumed to follow the AR (1) process. Assuming that the three factors move independently, only the principle diagonal elements in the covariance matrix of the state equation prediction error have values. The value of other elements is 0 .

The sensitivity of three factors is

$\left(1, \frac{1-\exp (-\tau \lambda)}{\tau \lambda}, \frac{1-\exp (-\tau \lambda)}{\tau \lambda}-\exp (-\tau \lambda)\right)$,

respectively.

They can be represented in the following figures according to maturity period. That is, the level factor had regular influence on all maturity periods. The slope factor had bigger influence on short-term maturity than a long-term one. The curvature factor is generally maximized in the intermediate-term maturity.

\section{A.2. Term Structure Data}

The input data was the spot yield curve of KTB (KOREA TREASURY BOND) government bonds. The period was from March 2002 to November 2012. The yield rate of the 20-year maturity bonds began to be reported in January 2006. Beginning in September 2012, the yield rate of the 30-year maturity bonds began to be reported. As the unit is not a percentage (\%), the value divided by 100 should be used for representing the percentage value.

Spot yield curve of KTB government bonds

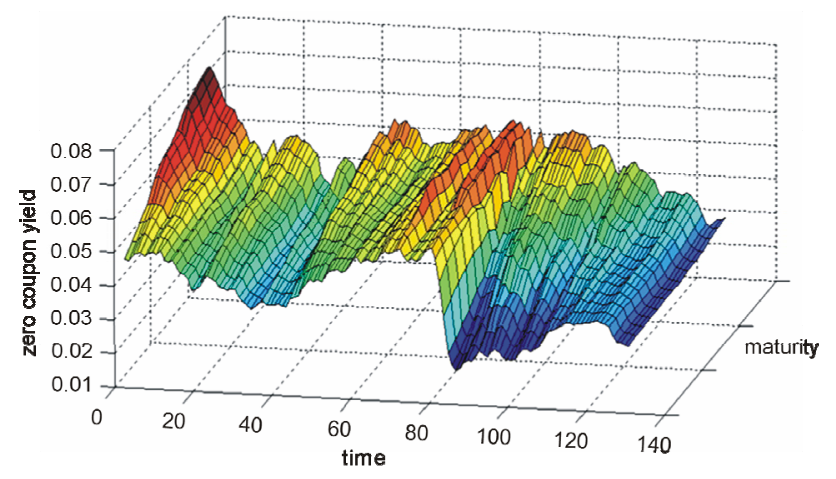

